\title{
CRACKING SUSCEPTIBILITY OF WELDED JOINTS IN REPAIR STRUCTURES ON MAIN GAS PIPELINES
}

\author{
V.S. BUT, S.Yu. MAKSIMOV and O.I. OLEJNIK \\ E.O. Paton Electric Welding Institute, NASU \\ 11 Bozhenko Str., 03680, Kiev, Ukraine. E-mail: office@paton.kiev.ua
}

\begin{abstract}
Repair of main pipelines under pressure involves application of various reinforcing welded structures. Operation periods of trunk lines in many cases are longer than 30 years, and pipe material can have an unfavourable structure, hence the need to broaden the concepts of ensuring the technological strength of welded joints under repair conditions. The work gives the results of studying the susceptibility of low-alloyed steel welded joints to cold and lamellar cracking. For this purpose, experiments were conducted on technological samples, simulating the real welded joints of repair structures. Positive impact of preheating, postweld heating and thermal annealing effect on cold cracking resistance is shown, as well as significant influence of sulphur on lamellar cracking susceptibility of steels. Possibility of prediction of lamellar cracking probability by the indices of reduction in area, impact toughness and critical crack opening displacement, as well as by delayed fracture critical stresses and fractographs of base metal fracture surface, is shown. 18 Ref., 2 Tables, 12 Figures.
\end{abstract}

$\boldsymbol{K} \boldsymbol{e} \boldsymbol{y} \boldsymbol{w} \boldsymbol{o r d} \boldsymbol{s}:$ repair welded structures, main pipelines, cold cracks, lamellar cracking, thermal annealing effect, technological samples

Ukraine has a powerful oil-and-gas complex that enables the country playing an important role in transportation of energy resources from supplier to consumer. Analysis of structural distribution of Ukraine's main gas pipelines (MGP) by their length shows that $23 \%$ of them have been in operation for more than 40 years, $32 \%$ - from 30 to 40 and $45 \%$ - up to 30 years [1]. It is understandable that ensuring the appropriate technical condition and continuous operation of pipelines in the near future will require a large scope of repair-reconditioning work.

Readiness for emergency situations and ability of taking action in these cases is an overimportant problem, from the moment of creating pressure in the pipeline and during its entire operation life. In this connection, each emergency or case of detection of inadmissible defects in pipeline linear part requires availability of a repair strategy, based on the following criteria: selection of repair method, safety of reconditioning operations performance, repair structure reliability (absence of cracks), environmental impact, uninterrupted product transportation, repair duration and cost-effectiveness. Preference should be given to procedures of repair without interruption of pipeline operation so as avoid reduction of pumped product volume or only slightly reduce it for a short time interval, and not cause considerable material-financial and environmental damage.
For Ukraine such methods are particularly important, in view of a high population density in MGP zone, high gas prices and need for unconditional fulfillment of contractual obligations on gas supply both to local and foreign users.

Performed diagnostics of technical condition of Company «Ukrtransgaz» MGP revealed extensive corrosion damage in the linear part, which is equal to about $50 \%$ of the total number of detected defects, individual areas of metal delamination, as well as defects in circumferential welded joints inadmissible by the currently valid normative-technical documents [2], which usually form in the closing butt joints («overlaps») in pipeline construction.

Proceeding from analysis of the nature and geometrical parameters of the detected defects, PWI proposed a structural approach to development of technologies for restoration of load-carrying capacity of MGP linear part under pressure with arc welding application [3]. Repair methods were grouped by defect kinds and purpose [4]. For each group safe conditions of welding performance were determined, allowing for working parameters of gas transportation, trunk line geometry, pipe metal mechanical properties and welded joint type.

The majority of the proposed methods for repair of MGP linear part in service [4] envisage application of reinforcing structural elements with typical welded joints (Figure 1). Before recommending the developed engineering solutions for practical application, it was necessary to determine the conditions of provision of welded joint technological strength, i.e. elimi- 

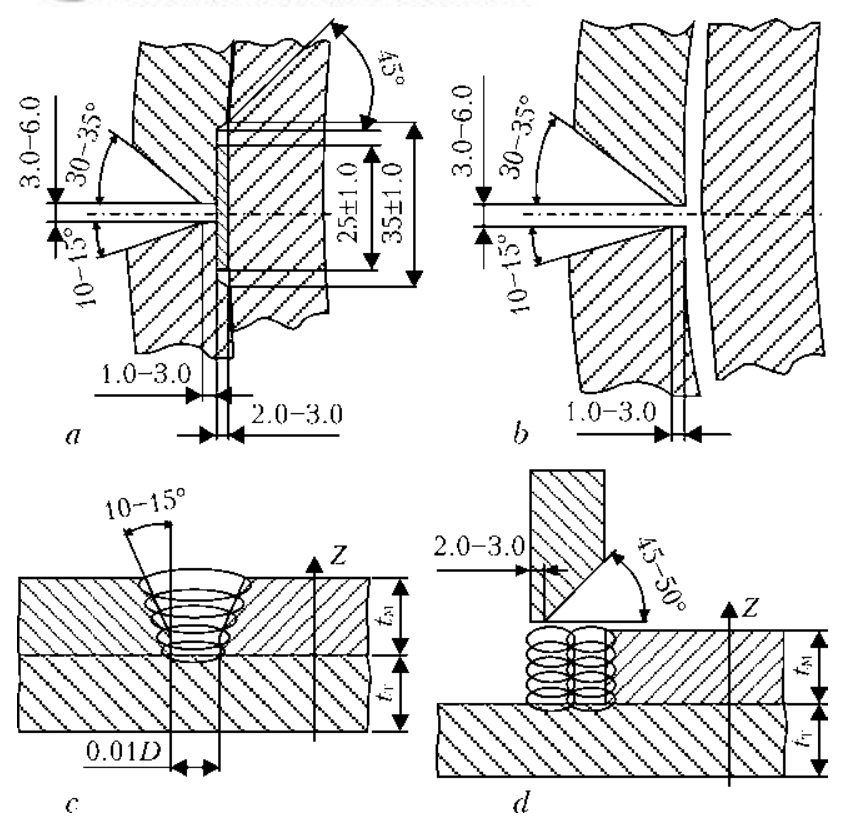

$c$

Figure 1. Typical welded joints in repair structures mounted on MGP in operation: $a, b-$ longitudinal butt weld of sleeve; $c$ - overlap-butt joint; $d$ - branchpipe-sleeve joint

nate cracking. Results of studies in this direction are presented in part in [5] which focused on evaluation of structural strength of welded joints of reinforcing elements to pipeline. This paper is devoted to technological aspects of pipe steel weldability.

Cold cracking resistance of welded joints. Ability of welded joints to stand thermomechanical impact without fracture (cold cracking) during stick electrode arc welding was evaluated on samples of pipe steels of typical grades $17 \mathrm{G} 1 \mathrm{~S}$ and X60, which were extensively applied in MGP construction in the 1980s of the previous century. This enabled a closer simulation of real welded joints of repair structures [4]. So, for longitudinal butt joints of sleeves (Figure 1, $a, b$ ) this was Tekken test sample; for overlap-butt joints of structural elements to pipeline (Figure 1, c) - Implant sample; for branchpipe-sleeve joints (Figure 1, d) - «window» sample; for «patch-sleeve» repair structure it was the circumferential sample. Table 1 gives the composition of the studied steels.

For comparative analysis of steels, allowing for preheating conditions ensuring the required cracking resistance, experiments were conducted on Tekken samples [6] from $16 \mathrm{~mm}$ thick plates, as thicker rolled stock is not yet applied for fabrication of reinforcing structural elements [7]. Thermocouples were welded to plate surface near the edge chamfers to determine the preheating temperature. Welding of control section of the joint was performed with $3 \mathrm{~mm}$ electrodes UONI$13 / 55$ with basic coating type and $3.2 \mathrm{~mm}$ Lincoln Electric Shield-Arc 65 electrodes with cellulose coating at base metal initial temperature of $20,50,100,150$ and $200{ }^{\circ} \mathrm{C}$. After welding macrosections were cut out of the control section for evaluation of crack presence/absence. Relative extent of cracks was determined in MBS-2 microscope as a ratio of crack length in the weld to total weld length.

Proceeding from the conducted studies graphic dependencies of relative extent of cracks $L_{\text {cr }}$ on preheating temperature $T_{\mathrm{pr}}$ were plotted (Figure 2). They showed that welded joints of X60 steel are more prone to cold cracking than those made on steel 17G1S. Application of cellulose coating electrodes significantly lowers crack resistance of both welded joints, because of high content of diffusible hydrogen, which can reach $40 \mathrm{~cm}^{3} / 100 \mathrm{~g}$ in deposited metal [8]. According to Tekken procedure, the optimum preheating temperature for prevention of cold cracking in real welded joints is selected by the criterion of total crack length of $50 \%$ in the control weld. Thus, in welding with electrodes with basic coating type $T_{\mathrm{pr}}=20-50$ and 70$100{ }^{\circ} \mathrm{C}$ for steel $17 \mathrm{G} 1 \mathrm{~S}$ and $\mathrm{X} 60$, respectively, and at application of electrodes with cellulose coating preheating temperature will be higher by $60-80{ }^{\circ} \mathrm{C}$ (see Figure 2).

In order to determine cracking conditions in welded joints of «patch-sleeve» repair structure [4] investigations were performed on a circular sample (Marine sample of US Department of the Marine) by the procedure of [6]. Minimum sample diameter was $100 \mathrm{~mm}$, sleeve width was $500 \mathrm{~mm}$. Results of investigation of the influence of gap $a$ between abutted elements of the structure and welding heat input $q$ on cold cracking susceptibility are shown in Figure $3, a$. Presence / absence of cracks was determined on trans-

Table 1. Composition of studied pipe steels

\begin{tabular}{|c|c|c|c|c|c|c|c|c|c|c|}
\hline \multirow{2}{*}{ Steel } & \multicolumn{9}{|c|}{ Composition, wt.\% } & \multirow{2}{*}{$\mathrm{C}_{\text {eq }}, \%$} \\
\hline & $\mathrm{C}$ & $\mathrm{Si}$ & Mn & $\mathrm{Cr}$ & $\mathrm{Ni}$ & S & $\mathrm{P}$ & V & $\mathrm{Nb}$ & \\
\hline $17 \mathrm{G} 1 \mathrm{~S}$ & 0.170 & 0.467 & 1.60 & 0.06 & 0.05 & 0.025 & 0.036 & 0.02 & 0.005 & 0.46 \\
\hline $\mathrm{X} 60$ & 0.121 & 0.219 & 1.54 & 0.10 & 0.05 & 0.011 & 0.027 & 0.04 & 0.051 & 0.41 \\
\hline Melt \#47 & 0.160 & 0.292 & 1.50 & 0.12 & 0.16 & 0.045 & 0.008 & 0.02 & 0.005 & 0.45 \\
\hline Melt \#65 & 0.148 & 0.179 & 1.49 & 0.11 & 0.07 & 0.030 & 0.007 & 0.02 & 0.005 & 0.33 \\
\hline
\end{tabular}


verse macrosections cut out of the closing quarter of the circular weld, where the highest tensile stresses are induced at weld metal shrinkage. It was obvious that the crack initiates at the stress raiser - in the point of deposited metal to base metal transition (Figure 3, b) and it is exactly in the zones of tensile stress concentration that diffusible hydrogen content increases markedly, promoting cold crack initiation [9].

From Figure 3 it is seen that with increase of the gap in the groove and respective increase of heat input, when making the root pass, cracks becomes shorter. At $a>8 \mathrm{~mm}$ practically no cracks form in welded joints of X60 steel. To eliminate the probability of cold cracking in weld metal of $17 \mathrm{G} 1 \mathrm{~S}$ steel circular sample, $a>6 \mathrm{~mm}$ is sufficient. Weld form factor $K_{\mathrm{w}}$ at maximum cracking is close to a unity, and in the absence of cracks $K_{\mathrm{w}} \sim 4$. As it is known, cold cracking resistance of welds also depends on their metal structure, which is related in a certain way to weld form factor [10].

Note that during testing of Marine samples the effect of additional cooling of welded joints during welding due to transported product was not taken into account. Therefore, when mounting such repair structures on MGP near compressor stations, under the conditions of intensive heat removal by gas flowing at a high speed, preheating up to 100$150{ }^{\circ} \mathrm{C}$ will be obviously required.

In our opinion, Implant test is the most effective method for evaluation of cold cracking resistance of low-alloyed steel welded joints [11]. This procedure allows for practically all the factors causing cold cracking, namely low-ductility structure of HAZ metal, high level of tensile stresses, presence of stress raiser and significant

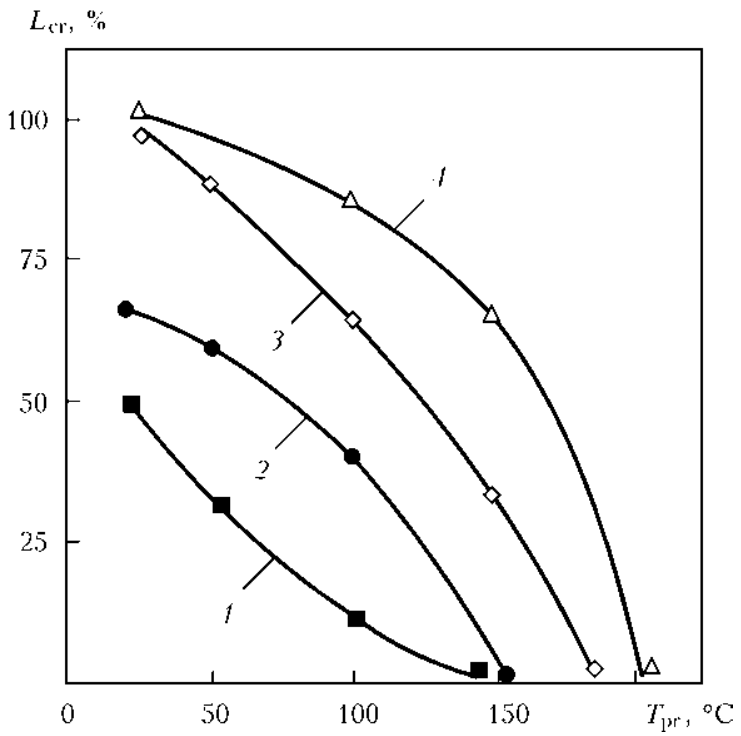

Figure 2. Dependence of crack length on preheating temperature, electrode coating type and steel grade for Tekken test weld: 1, 3-17G1S steel; 2, $4-\mathrm{X} 60 ; 1,2-\mathrm{UONI}$ $13 / 45$ electrodes; $3,4-$ Shield-Arc 65

content of diffusible hydrogen. High tensile stresses, which are induced at raisers of geometrical origin (this, for instance, is the interlayer gap in overlap-butt joints of reinforcing elements to the pipeline), even at low hydrogen level, may lead to cold crack initiation and furtheron to welded joint fracture at long-term loading.

Experiments were conducted in keeping with IIW recommendations [11] for two variants. In the first case, samples were cut out of plates of $17 \mathrm{G} 1 \mathrm{~S}$ and X60 steels along the rolling direction, in order to study the influence of structural factor, diffusible hydrogen and welding technique on critical stresses at delayed fracture of welded samples in AIMI-5 testing machine. In the second case Im-
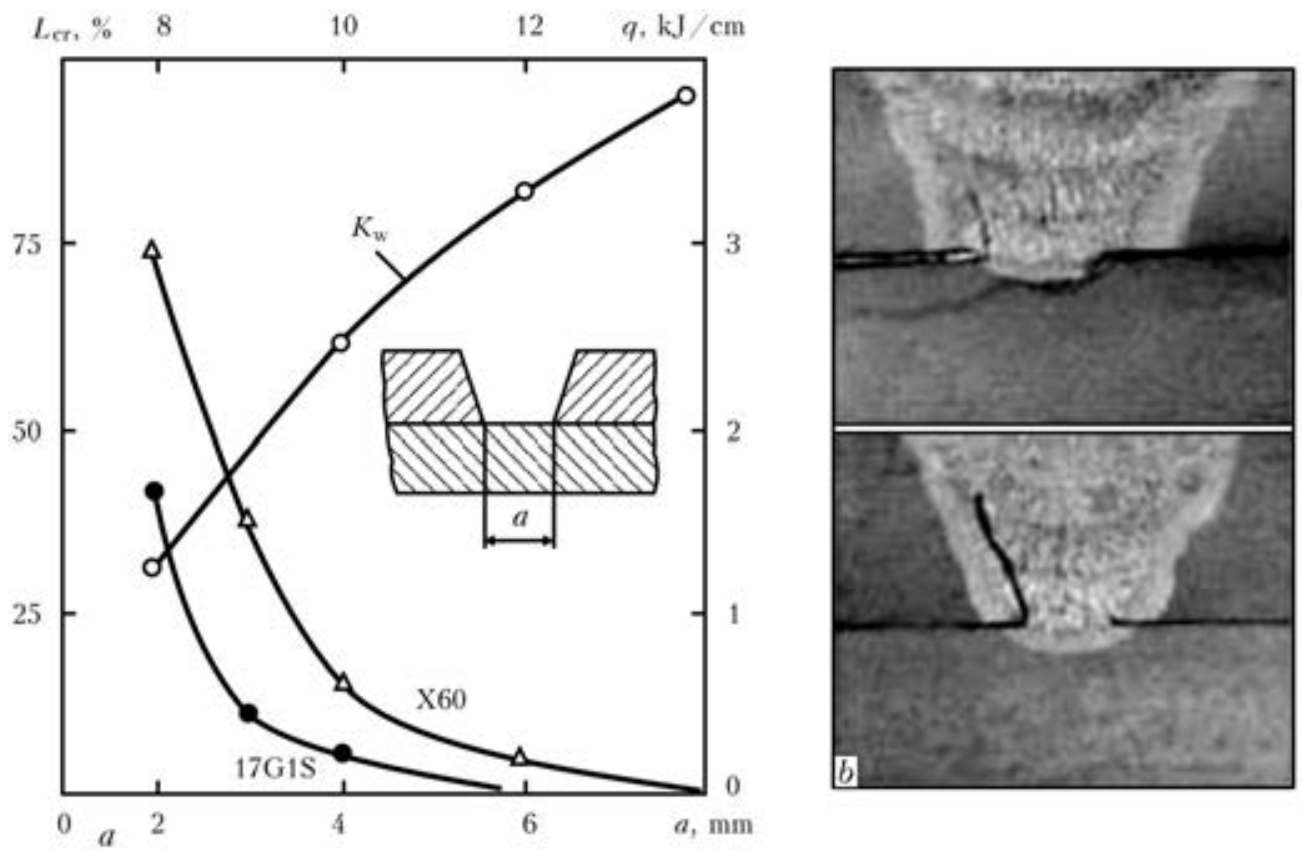

Figure 3. Conditions of crack initiation in circular sample $(a)$, and crack initiation region $(b)$ 


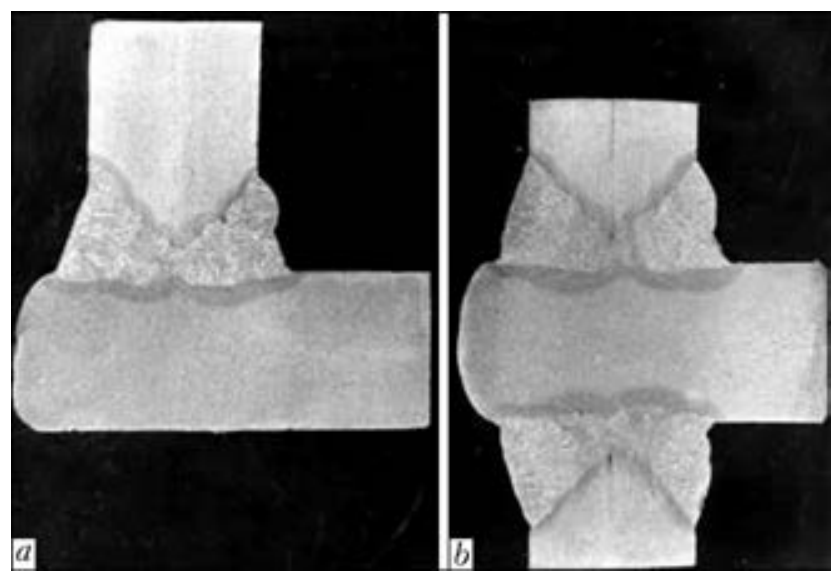

Figure 4. Macrosections of welded joints for preparing composite Implant samples with notch parallel to rolling direction for testing by tension along $Z$ axis $(a)$; for impact toughness and crack opening displacement $(b)$

plant samples were cut out of tee-joints (Figure 4) of all the examined steels to study the influence of diffusible hydrogen and impurities (sulphur) on cold cracking susceptibility under the impact of stresses in the direction normal to metal texture.

Welding of samples simulating real welded joints of repair structures (Figure 5) was performed with stick electrodes of 3.0 and $3.2 \mathrm{~mm}$ diameter with basic and cellulose coating in the following mode: $I_{\mathrm{w}}=110-120 \mathrm{~A}, U_{\mathrm{a}}=24-26 \mathrm{~V}$, $v_{\mathrm{w}}=1.9-2.5 \mathrm{~mm} / \mathrm{s}$, ensuring heat input $q=$ $=0.8-1.2 \mathrm{~kJ} / \mathrm{mm}$. In two-pass welding the thermally annealing layer was deposited with the heat input 1.4-1.7 times higher than that in single-pass welding. After weld metal cooling to

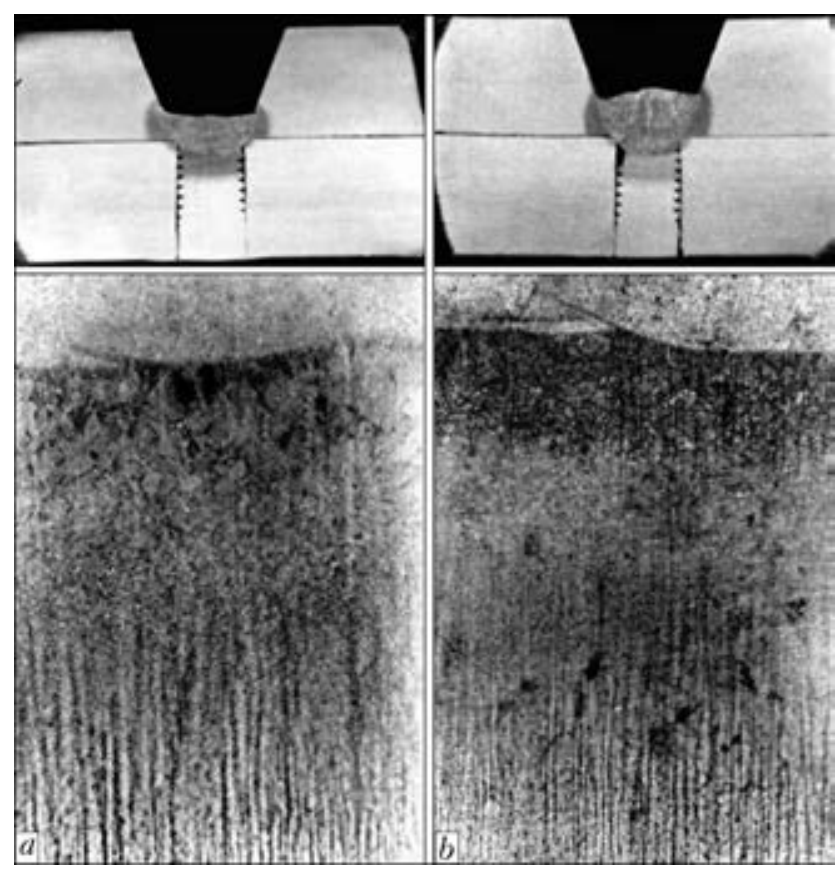

Figure 5. Single- $(a)$ and two-pass $(b)$ welding of Implant samples to produce joints simulating the real ones
$100{ }^{\circ} \mathrm{C}$, the samples were tested by constant loading in a standard machine.

Critical stresses not leading to sample cracking for $16 \mathrm{~h}$ were taken as the criterion of evaluation of welded joint cold cracking resistance. Diffusible hydrogen content in weld metal was determined by chromatographic method [12] on samples made under identical conditions.

It is established that in joints welded with Shield-Arc 65 electrodes diffusible hydrogen content $[\mathrm{H}]_{\text {diff }}=19-24 \mathrm{~cm}^{3} / 100 \mathrm{~g}$. In their turn, UONI $13 / 55$ electrodes after baking at $380-$ $400{ }^{\circ} \mathrm{C}$ ensure the level of $5.0-7.4 \mathrm{~cm}^{3} / 100 \mathrm{~g}$, and without baking (after soaking in air with relative humidity of $90 \%$ for more than 3 days) a significant increase of hydrogen content in the deposited metal was noted - up to $[\mathrm{H}]_{\text {diff }}=$ $=12-16 \mathrm{~cm}^{3} / 100 \mathrm{~g}$.

By the results of testing welded Implant samples, cut out of the studied steels along the rolling direction, graphic dependencies of variation of delayed fracture stresses in time were plotted for different content of diffusible hydrogen in the deposited metal, as well as for the case of application of thermally annealing layer (Figure 6, $a$ ). These graphs confirmed running of delayed fracture in samples, welded in one pass, and leading role of hydrogen in this process. With increase of diffusible hydrogen content critical fracture stress decreases, and duration of incubation period of crack initiation is also reduced. This is readily illustrated by fracture surface of Implant samples (Figure 7). Application of electrodes with basic coating type without baking (see Figure $6, a$; curve 6 ) leads to lowering of joint crack resistance almost to the level of values derived at application of cellulose coating electrodes (curve 2). Use of thermal annealing effect at deposition of the weld second layer (curve 3) allows lowering the probability of delayed fracture, owing to improvement of HAZ microstructure (see Figure 5, b) and, obviously, lowering diffusible hydrogen content in deposited metal.

When testing samples with a mechanical notch, made along the rolling direction ( $\mathrm{Fi}^{-}$ gure $8, a)$, combined influence of hydrogen and nonmetallic inclusions (by sulphur content) on cracking resistance was studied. For this purpose, test PWI melts of low-alloyed steels (see Table 1) were used in addition to batch-produced pipe steels. The composition of these melts was changed by variation of the content of main alloying elements (carbon, silicon, manganese), as well as sulphur.

Results of testing composite Implant samples showed (see Figure $6, b$ ) that the nature of delayed fracture resistance of pipe steels changed essentially, compared to the case of load appli- 

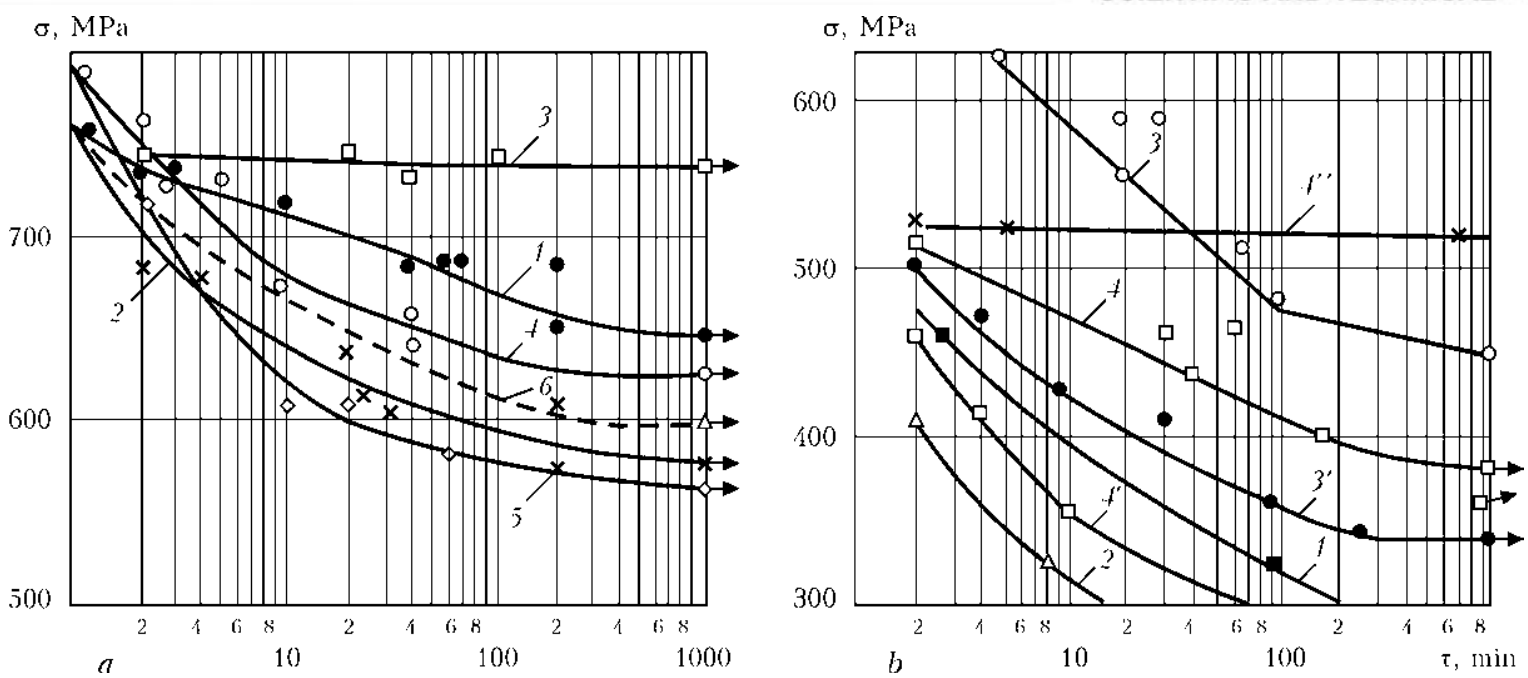

Figure 6. Results of testing Implant samples for long-term strength at loading along rolling direction $(a$ : $1,4-\mathrm{UONI}$ $13 / 55$ electrodes after baking, $[\mathrm{H}]_{\text {diff }}=4.0-7.4 \mathrm{~cm}^{3} / 100 \mathrm{~g} ; 2,5-$ Shield-Arc $65,[\mathrm{H}]_{\mathrm{diff}}=19-24 \mathrm{~cm}^{3} / 100 \mathrm{~g} ; 3-$ thermal annealing pass; 4, $6-$ UONI 13/55 without baking, $[\mathrm{H}]_{\text {diff }}=12-16 \mathrm{~cm}^{3} / 100 \mathrm{~g} ; 1-3,6-17 \mathrm{G} 1 \mathrm{~S}$ steel; 4, $5-\mathrm{X} 60)$ and along $Z$ axis ( $b: 1$ - melt \#65; 2 - \#47; 3 - X60 steel; 4 - 17G1S; $1-4,4^{\prime \prime}$ - UONI 13/55 electrodes; $3^{\prime}, 4^{\prime}$ - Shield-Arc $65 ; 4^{\prime \prime}$ - postweld heating)

cation along the rolling direction (Figure 6, $a$ ). Welded joints of X60 steel (Figure 6, $b$; curves 3, 3') demonstrate higher cracking resistance than $17 \mathrm{G} 1 \mathrm{~S}$ steel joints (curves $4,4^{\prime}$ ). This, in our opinion, is related to lower content of sulphur and absence of stringer structure in base metal, although absolute values of delayed fracture critical stresses were much lower than for Implant samples with a notch across metal rolling direction. Fracture mode of $17 \mathrm{G} 1 \mathrm{~S}$ steel samples with a high content of diffusible hydrogen in the deposited metal after the applied heating and soaking at $150{ }^{\circ} \mathrm{C}$ for $16 \mathrm{~h}$ is illustrated by Figure 8 , $b, c$. Note that after removal of hydrogen from the HAZ, samples failed in the base metal in sections weakened by nonmetallic inclusions (Figure 8,c), critical fracture stresses were at a high enough level (see Figure 6, b, curve 4"), sample fracture at initial content of diffusible hydrogen ran through the HAZ (Figure $8, b$ ).

Under the effect stresses applied across metal thickness (notch parallel to rolling direction), the simultaneous negative influence of diffusible hydrogen and nonmetallic inclusions (sulphides) on delayed cracking resistance of welded joints is manifested. Hydrogen accumulates in voids containing inclusions, transforming from atomic into molecular form, and creates high pressure in them, thus facilitating metal matrix destruction at small radii of curvature of inclusion edges (considerable stress concentration on matrix-inclusion boundary). This is confirmed by the results of testing other experimental steels with different sulphur content (see Figure $6, b$; curves $1,2)$ and of fractographic analysis of fracture surface of Implant samples (Figure 9) in scanning electron microscope JEOL JSM-35CF. Studies showed that $17 \mathrm{G} 1 \mathrm{~S}$ steel samples are characterized by coarse-cellular structure, containing sulphide and sulphosilicate nonmetallic inclusions of ellipsoidal, globular and plate-like shape (Figure 9, $a$ ). Structure of X60 steel is finegrained with a small quantity of globular-shaped nonmetallic inclusions of less than $2 \mu \mathrm{m}$ size ( $\mathrm{Fi}-$
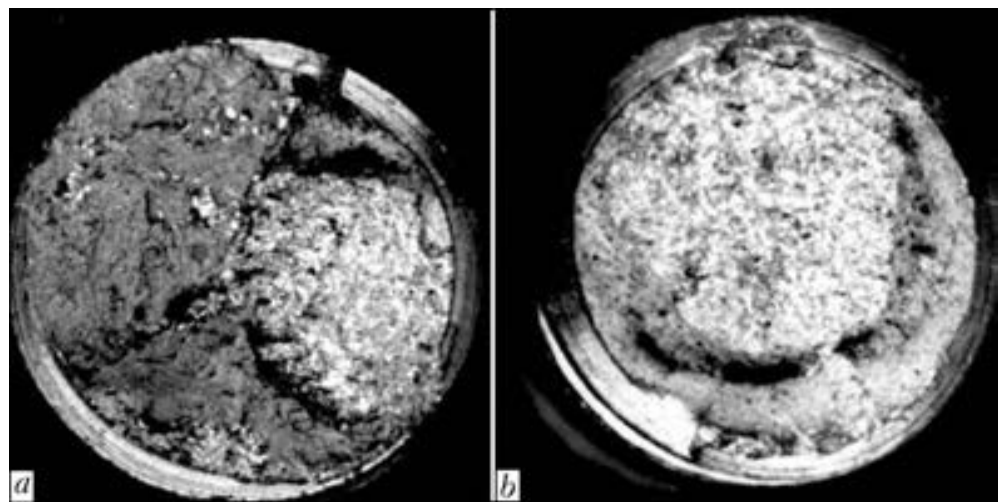

Figure 7. Fracture surface $(\times 10)$ of Implant samples from X60 steel, welded with Shield-Arc 65 electrodes: $a-\sigma=$ $=615 \mathrm{MPa}, \tau=40 \mathrm{~min} ; b-\sigma=565 \mathrm{MPa}, \tau=100 \mathrm{~min}$ 


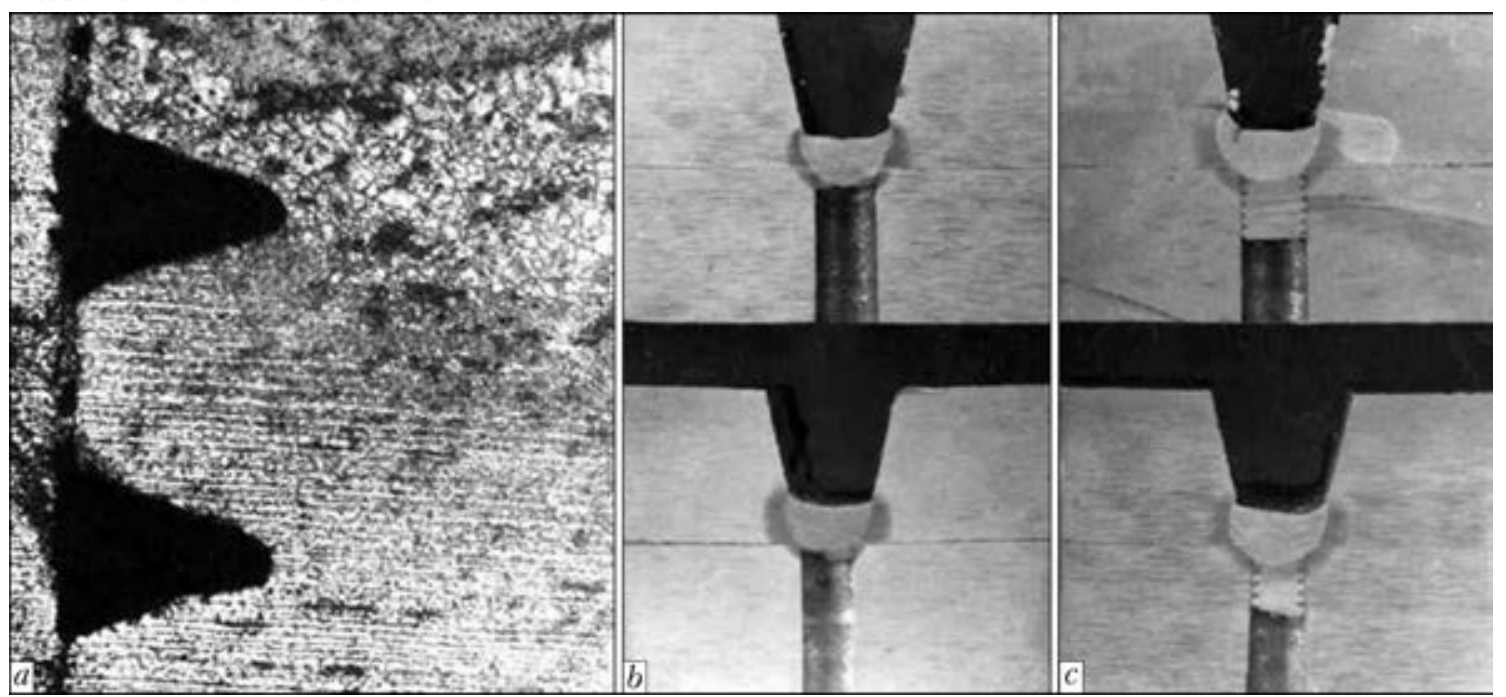

Figure 8. Notch location in HAZ of Implant sample $(a-\times 63)$, fracture through the HAZ $(b)$ and base metal $(c)$

gure $9, b)$. A considerable quantity of plate-like nonmetallic inclusions is observed on fracture surface of steel from melt \#47 (Figure 9,c) with the highest sulphur content (see Table 1).

Thus, summing up the results of testing welded joints for cold cracking resistance leads to the following conclusions. First, repair operations in operating MGP should be performed with application of electrodes with a basic coating, ensuring a low content of diffusible hydrogen in the deposited metal. Secondly, thermal annealing effect of multilayer weld second pass, which improves HAZ microstructure and ensures partial evacuation of hydrogen from problem zone, should be used. Thirdly, postweld heating should be performed for joints, in which loads can be applied later on in the direction normal to pipe metal texture. And, finally, traditional preheating up to $100-150{ }^{\circ} \mathrm{C}$ is required under the conditions of intensive heat removal in the repaired MGP section.

Evaluation of welded joint susceptibility to lamellar cracking. Lamellar cracking is one of the most common kinds of cracks in welded structures. Determination of material susceptibility to lamellar cracking is an important aspect of evaluation of low-alloyed steel weldability. Steplike form of cracks and their location, mainly, outside the HAZ, allows distinguishing these cracks from cold cracks. It is characteristic that such precautions as preheating and application of low hydrogen electrodes, that are effective for cold crack prevention, have an only slight influence on the probability of lamellar crack initiation.

As shown by world experience, overlap-butt and tee welded joints of low-alloyed steels can develop lamellar cracking at application of tensile stresses across the rolling stock direction. This problem is urgent also for welded joints of
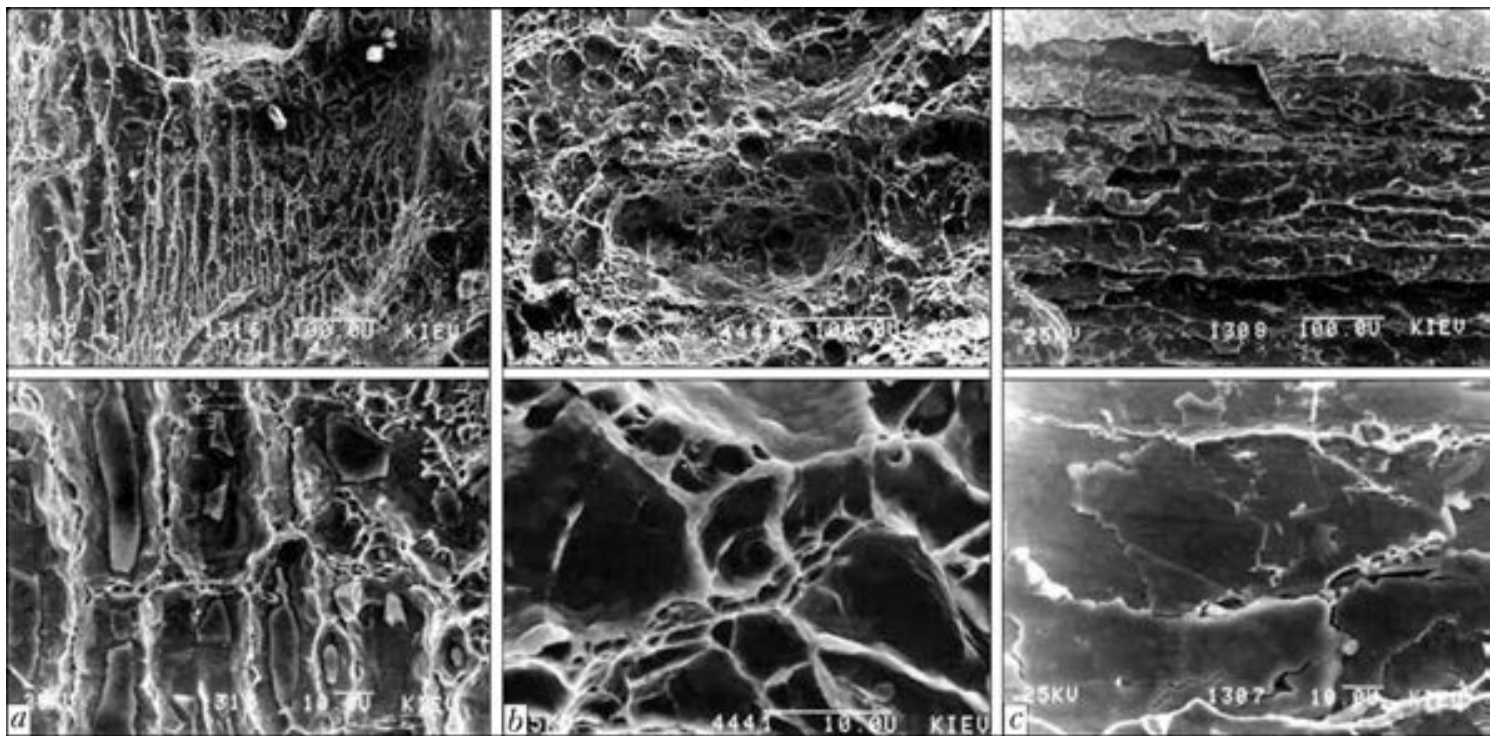

Figure 9. Fractographs of fracture surface of samples failing along $Z$ axis: $a-17 \mathrm{G} 1 \mathrm{~S}$ steel; $b-\mathrm{X} 60 ; c-$ melt \#47 (upper row $-\times 300$, lower row $-\times 3000$ ) 
structures (reinforcing sleeves, tee-pieces), mounted on MGP in service, as lowering of inner pressure in the pipeline in circumferential overlap-butt joints induces considerable radial stresses that is related to different deformability of welded shells.

It is also known [13] that lamellar cracking susceptibility of welded joints is influenced by the following factors:

- high content of nonmetallic inclusions of the type of manganese and iron sulphides and oxysulphides;

- unfavourable morphology of nonmetallic inclusions;

- weakening of metal matrix because of the high content of nonmetallic inclusions in one rolled stock plane;

- considerable extent of fusion boundaries along the rolling direction (parallel to metal texture);

- stress application across the rolled stock thickness ( $Z$ axis).

Steels of different strength classes (20, 09G2S, X70) were additionally used for evaluation of lamellar cracking susceptibility of base metal. Experiments were performed on cylindrical composite samples with gauge diameter of $6 \mathrm{~mm}$, which were made from cruciform welded joints (see Figure $4, b$ ). Six samples of each steel grade were prepared and tested at uniaxial tension, when in the studied metal section stresses are applied along $Z$ axis. After breaking of cylindrical samples reduction in area $\psi$ in the fracture butt was measured in keeping with the procedure of [13]. Derived results are given in Table 2 .

For illustration purposes a histogram of steel distribution by reduction in area was plotted by average values of this characteristic (Figure 10). Steels 20, X60, X70 have the highest ductility at application of stresses across sheet thickness, and, hence lower lamellar cracking susceptibility, and $17 \mathrm{G} 1 \mathrm{~S}$ and test melts \#65 and 47 are the least susceptible.

Fractographs of fractures of Implant samples failing through base metal also characterize steel ductility in the direction of axis $Z$. Using criteria proposed in [13], derived results can be assessed as follows (Table 2): formation of lamellar cracks in welded joints of steels 20 and X70 is improbable $(\psi \geq 25 \%)$; for $17 \mathrm{G} 1 \mathrm{~S}, 09 \mathrm{G} 2 \mathrm{~S}$ and $\mathrm{X} 60$ steels testing of reference «window» type restrained joints $(15 \leq \psi<25 \%)$ is required; steels of melts \#47 and 65 are prone to lamellar cracking and are not recommended for fabrication of critical welded structures $(\psi<15 \%)$.

Influence of sulphur content on physico-mechanical properties of metal was studied with the notch made parallel to rolling direction that also characterizes steel susceptibility to lamellar cracking [14]. Toughness evaluation was performed on Mesnager samples at shock loading,
Table 2. Results of testing composite samples for lamellar cracking susceptibility

\begin{tabular}{|c|c|c|}
\hline Steel & $\sigma_{\mathrm{t}}, \mathrm{MPa}$ & $\psi, \%$ \\
\hline 17G1S & $\frac{504-546}{516}$ & $\frac{11.0-17.6}{14.7}$ \\
\hline X60 & $\frac{572-580}{574}$ & $\frac{20.2-26.0}{23.2}$ \\
\hline Melt \#47 & $\frac{420-480}{452}$ & $\frac{6.1-11.3}{7.4}$ \\
\hline Melt \# 65 & $\frac{464-510}{485}$ & $\frac{10.0-14.2}{13.0}$ \\
\hline 20 & $\frac{466-480}{469}$ & $\frac{22.1-30.6}{25.7}$ \\
\hline 09G2S & $\frac{470-492}{481}$ & $\frac{19.0-27.2}{20.3}$ \\
\hline X70 & $\frac{642-660}{648}$ & $\frac{21.6-28.2}{26.1}$ \\
\hline
\end{tabular}

and brittle fracture susceptibility was determined on samples which allowed recording crack opening displacement (COD) at three-point bending. All the samples were cut out of cruciform welded joints (see Figure 4, b). Results of testing composite samples are given in Figure 11. One can see that impact toughness of metal decreases with increase of its sulphur content, particularly at negative temperatures (Figure 11, $a$ ). As regards pipe steels, X60 has higher characteristics than $17 \mathrm{G} 1 \mathrm{~S}$, which has more sulphur (see Table 1). This is another confirmation of conclusions of [14] that sulphur content in steel above $0.012 \%$ lowers welded structure reliability.

Preparation and testing of samples for COD determination was performed in keeping with procedure of [15]. Similar temperature dependencies were derived from COD which characterizes brittle fracture resistance of metal under static three-point loading of samples with a notch parallel to rolling direction (Figure 11, b). Graphs demonstrate that steel of melt \#47

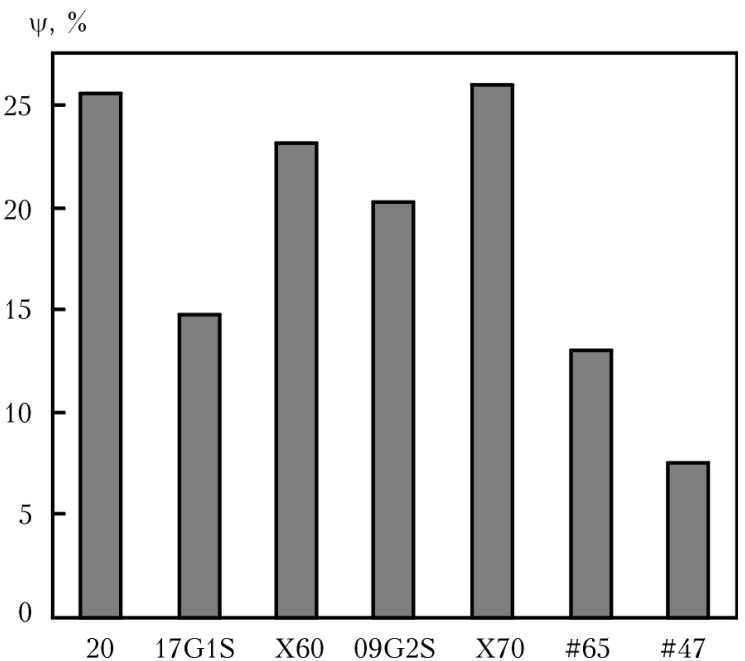

Figure 10. Steel distribution by the characteristic of lamellar cracking susceptibility depending on relative reduction along $Z$ axis 

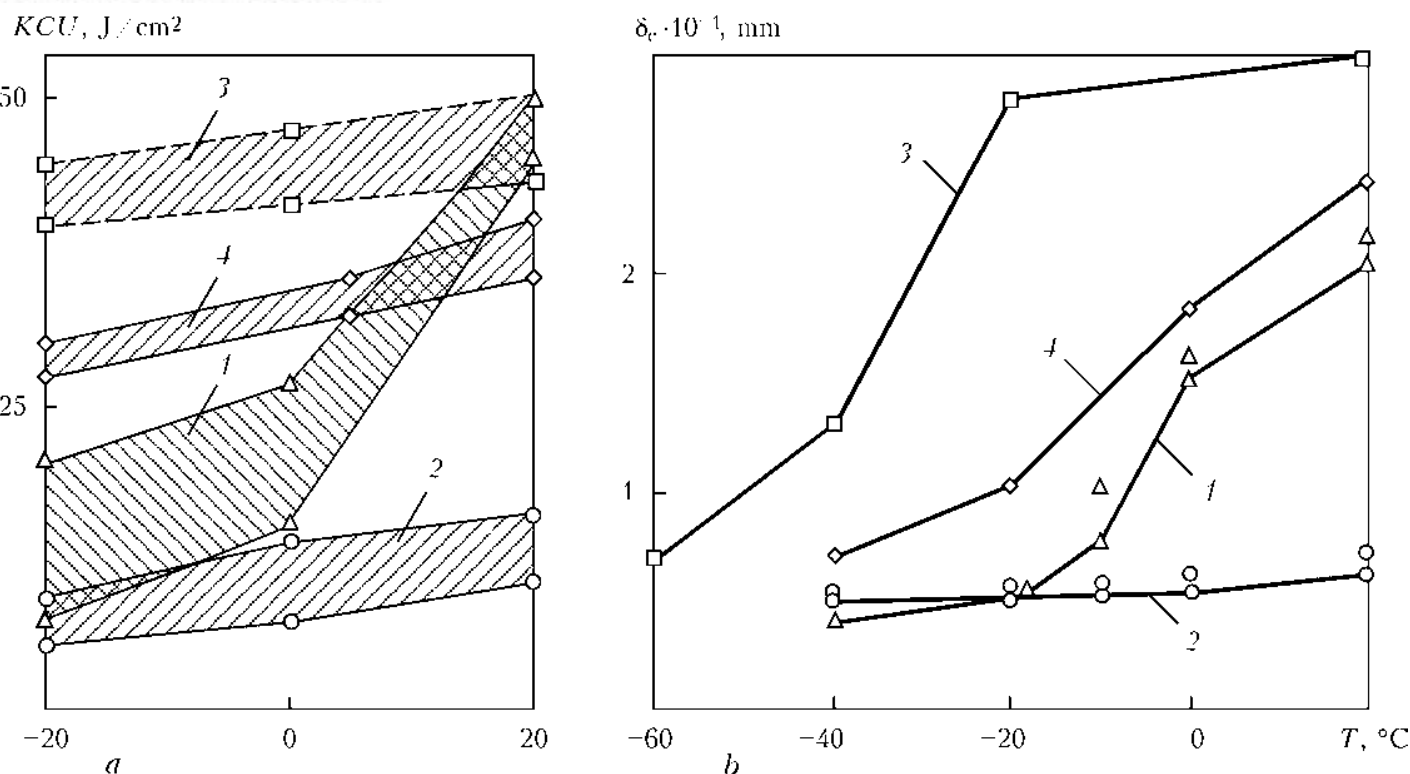

Figure 11. Toughness of samples with notch along rolling direction at shock loading $(a)$ and three-point bending $(b)$ : 1 - melt \#65; 2 - \#47; 3 - steel X60; 4 - 17G1S

(curve 2) with high sulphur content has very low COD values at three-point bending in the entire testing range and by the criterion of brittle frac-

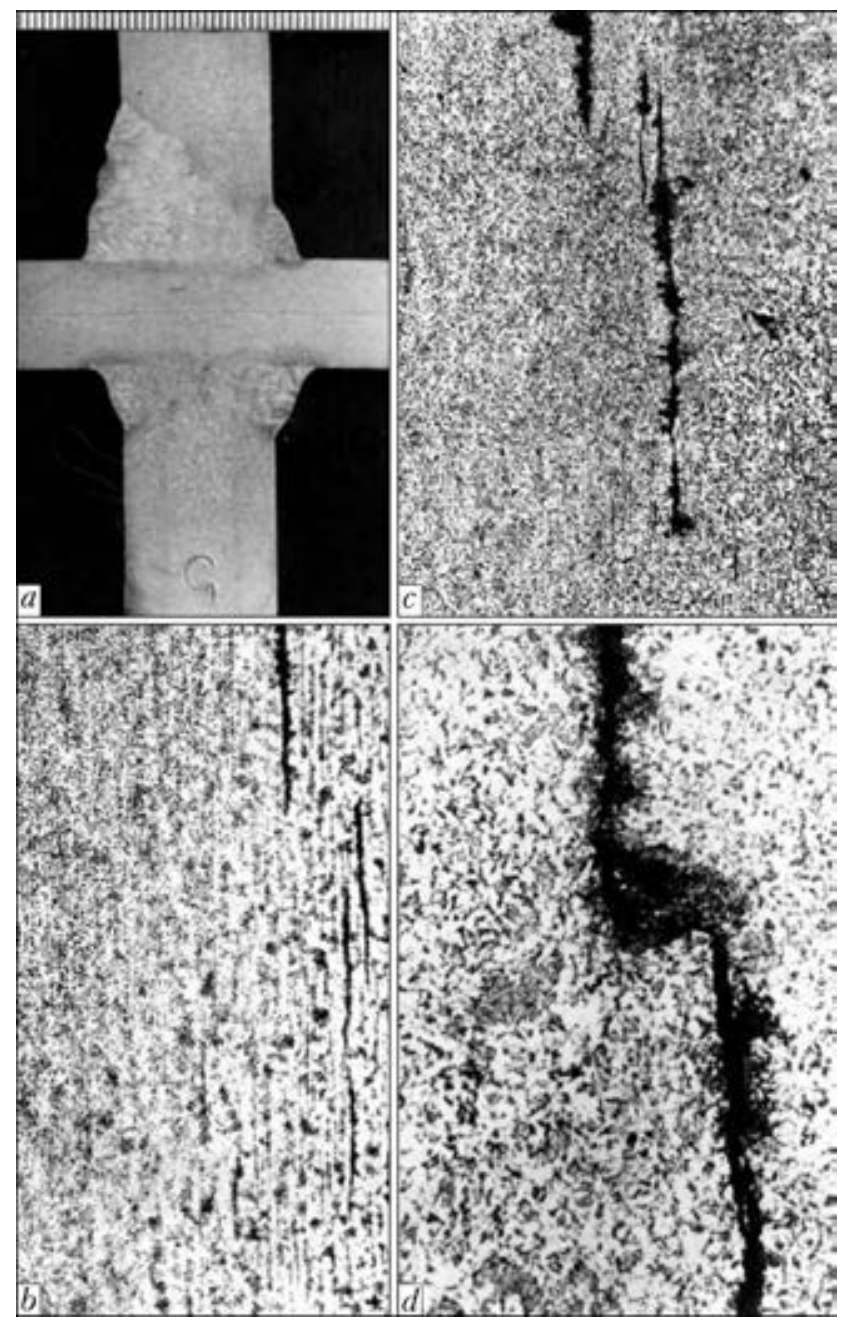

Figure 12. Macrosection of «window» sample $(a)$, lamellar cracking in base metal $(b-\times 100)$ and HAZ $(c-\times 100$; $d-\times 500)$ ture resistance of metal $\left(\delta_{\mathrm{c}}>0.12 \mathrm{~mm}\right)$ it cannot be applied for fabrication of critical welded structures. Steel of melt \#65 (curve 1) under the conditions of application of tensile stresses across sheet thickness can be in service only at above zero temperatures, $17 \mathrm{G} 1 \mathrm{~S}$ steel (curve 4 ) - at temperatures down to $-15{ }^{\circ} \mathrm{C}, \mathrm{X} 60$ (curve 3) down to $-40{ }^{\circ} \mathrm{C}$.

$17 \mathrm{G} 1 \mathrm{~S}$ steel, having intermediate values of toughness and ductility from those obtained on all the composite samples, was selected to verify welded joint susceptibility to lamellar cracking. It was used to make a sample, welded into a slot on a rigidly restrained $25 \mathrm{~mm}$ thick plate of $300 \times$ $\times 300 \mathrm{~mm}$ size from 09G2S steel. This sample, according to [16], is called «window» sample and allows inducing in studied metal a high level of tensile stresses across the rolling direction at shrinkage of closing multilayer weld in $\mathrm{V}$-shaped groove. Macrosection of this welded joint and formation of lamellar cracking in it are shown in Figure 12. Cracks are located in base metal, HAZ and at a certain distance from it. It is seen that crack opening occurred in points of location of nonmetallic inclusions of unfavourable plate-like shape with sharp edges.

Thus, for pipelines, manufactured from steels of such composition, after repair structures have been welded-on without interrupting pipeline operation, considerable internal pressure gradients are inadmissible, and in case of mounting reinforcing elements design-technological measures should be envisaged which lower lamellar cracking probability. The most effective method to reduce lamellar cracking susceptibility is regulation of sulphur content in steel in melting by addition of rare-earth elements, which not only are active deoxidizers, but also bind sulphur into finely-dispersed globular particles of oxysul- 
phides and sulphides, uniformly distributed in steel. As was mentioned above, residual sulphur content in steel should not be higher than $0.012 \%$ and REM:S ratio should be $\geq 4: 1$ [14]

Repair operations are performed on MGP built a long time ago, and pipe steel used in them is not quite favourable by its composition in terms of weldability, so that welders have to apply designtechnological measures for prevention of lamellar cracking of repair structures. One of such approaches, tried out in practice, is pre-deposition of a buffer layer of less strong metal than that of the weld that was the basis for engineering solution of connecting branchpipes to MGP in operation [17]. Preliminary cutting out of pipe wall surface layer with subsequent filling of the groove by welding consumable, ensuring weld strength equivalent to that of base metal, can be regarded as another effective solution at repair [18].

In this connection, performance of research to evaluate the effectiveness of local remelting of surface layer of pipe wall under pressure by argon-arc or plasma method to reduce nonmetallic inclusion content in the produced welded joints and, therefore, lowering the lamellar cracking probability, is promising.

\section{Conclusions}

1. Comparative testing with application of Tekken sample showed higher crack resistance of welded joints of $17 \mathrm{G} 1 \mathrm{~S}$ steel than that of X60 steel. It is found that in welding with basic coating electrodes, preheating temperature should be $20-50{ }^{\circ} \mathrm{C}$ for $17 \mathrm{G} 1 \mathrm{~S}$ steel and $70-100{ }^{\circ} \mathrm{C}$ for X60 steel in order to prevent cold cracking. At application of electrodes with cellulose coating the temperature should be increased by $60-80{ }^{\circ} \mathrm{C}$.

2. Testing of Implant samples with a notch along and across the rolling direction showed differences in delayed cracking resistance of steel. In the first case, because of simultaneous negative influence of diffusible hydrogen and sulphide inclusions cold cracking resistance of X60 steel is higher than that of $17 \mathrm{G} 1 \mathrm{~S}$ steel. In the second case $171 \mathrm{GS}$ steel had higher values of critical breaking stresses.

3 . By the results of testing samples for tension along $Z$ axis the studied steels were ranged by their lamellar cracking susceptibility in the joint zone, depending on sulphur content.

4. Possibility of prediction of lamellar cracking probability by the following parameters was established: reduction along $Z$ axis, impact toughness and crack opening displacement on samples with a notch along the rolling direction; delayed fracture critical stress; base metal fracture surface fractographs.

5. To lower the risk of cold cracking during repair performance in operating MGP, it is nec- essary to apply electrode materials, ensuring a low content of diffusible hydrogen in the deposited metal, use thermal annealing effect from the previous pass of multilayer weld, perform welded joint postweld heating in the case of load application in the direction normal to pipe surface.

6 . To prevent lamellar cracking in repair structures on main pipelines it is rational to first perform deposition of a buffer layer of less strong metal or cutting out the pipe wall surface layer with its subsequent filling by welding consumable ensuring equivalent strength of welded joint.

1. But, V.S., Gretsky, Yu.Ya., Rozgonyuk, V.V. (2001) Substantiation of new approach to realize welding operations on pipelines under pressure. Naft. $i$ Gaz. Promyslovist, 4, 33-39.

2. Drogomiretsky, M.M. (2006) In-pipe diagnostics of main gas pipelines and repair of detected defects. In: Proc. of Sci. Seminar on Reliability Assurance of Pipeline Transport Systems (Kiev, 11 April 2006). Kiev: Ekotekhnologiya.

3. But, V.S., Olejnik, O.I. (2007) Main trends in technology for repair of active pressurized main pipelines. The Paton Welding J., 5, 30-35.

4. GBN V.3.1-00013741-12:2011: Main gas pipelines. Repair arc welding in service conditions. Introd. 06.09.2011. Kiev: Ministry of Energy and Coal Industry of Ukraine.

5. But, V.S., Olejnik, O.I. (2011) Evaluation of technological and structural strength of welded joints of structures to be repaired on main pipelines. In: Proc. of Sci.-Pract. Conf. on Residual Resource and Problems of Modernization of Systems of Main and Commercial Pipelines (Kiev, 12-13 April 2011). Kiev: PWI.

6. Shorshorov, M.Kh. Chernyshova, T.A., Krasovsky, A.I. (1972) Weldability testing of metals. Moscow: Metallurgiya.

7. TU U 27.2-19305558-001:2007: Structural reinforcing elements of pipelines. Valid from 03.07.2007.

8. (1998) Kobelko Welding Today, 2, 2.

9. Makarov, E.L. (1981) Cold cracks in welding of alloy steels. Moscow: Mashinostroenie.

10. (1974) Technology of electric fusion welding of metals and alloys. Ed. by B.E. Paton. Moscow: Mashinostroenie.

11. Granjon, H.J. Recommendation for the use of Implant test as a complementary information test on the cold cracking susceptibility during the welding of steels. IIW Doc. IX 830-73.

12. GOST 23338-91: Welding of metals. Methods for determination of diffusion hydrogen content in deposited and weld metal. Introd. 01.07.92. Moscow: Gosstandart SSSR.

13. Suzuki, H. (1983) Weldability of modern structural steels in Japan. Transact. Iron and Steel Inst. of $\mathrm{Ja}^{-}$ pan, 23(3), 189-204.

14. Vikhlevshchuk, V.A., Chernogritsky, V.M., Fedorova, I.P. (1989) Improvement of reliability of welded structures by reduction of sulfur content in steel. Avtomatich. Svarka, 4, 1-6.

15. Kirian, V.I. (1984) Method of evaluation of structural steel resistance to ductile fracture. Ibid., 11, 1-6.

16. Farrar, J.C.M., Dolby, R.E., Baker, R.G. (1969) Lamellar tearing in welded structural steels. Welding J., 7, 274-282.

17. But, V.S., Marchuk, Ya.S., Mandra, A.S. Method of joining of branchpipe to gas pipeline in service. Pat. 40033 Ukraine. Int. Cl. F16L 41/00. Publ. 25.03.2009.

18. But, V.S. Maksimov, S.Yu., Olejnik, O.I. et al. Process of liquidation of technological opennings in main pipelines. Pat. 11796 Ukraine. Int. Cl. F16L $55 / 16$, E21F5 $/ 00$. Publ. 16.01.2006.

Received 05.06.2014 